\title{
The Development of Online Children Skin Diseases Diagnosis System
}

\author{
Munirah M. Yusof, Ruhaya A. Aziz, and Chew S. Fei
}

\begin{abstract}
Human habits tend to assume that certain skin diseases are not severe problem. If their children skin had been infected by certain skin diseases, most of the parents or guardian will try to treat this infected skin on their own. However, sometimes this treatment was not suitable with that particular skin problem and can make it become worse. This paper proposes a development of an Online Children Skin Diseases Diagnosis System. This system enables user to recognize skin diseases faced by children through online and provide user advises or treatments in shorter time period. To do so, user will answer questions based on their skin condition or symptoms. It will then helps in detecting the skin diseases and provide treatment suggestion. A rule based and forward chaining inference engine has been used for the development of the system. With this system, it help and allows user recognize children skin diseases via online system and provide useful suggestion to user.
\end{abstract}

Index Terms-Children skin diseases, rule based, expert system.

\section{INTRODUCTION}

Skin diseases are diseases that may originate inside the body and manifest on the skin or start from the skin and manifest on the skin [1]. Some common skin diseases are eczema and rash can infected children and adults. For instances, Atopic Eczema can affects 2 in every 10 people in Malaysia and about $10 \%-14 \%$ of children below the age of 14 [2]. Basically, if children skin had been infected by certain skin diseases, most of the parents or guardian will try to treat this infected skin on their own. However, apparently this treatment was not suitable with that particular skin problem and can make it become worse. These cause disruption for children during their daily routine especially for those children that started attending school.

Human habit tend to assume that certain skin diseases are not severe problem, and they tend to not seeing the medical expert in helping diagnose skin diseases. One more problem with skin disease is the difficulty in recognizing the main cause. This occurs because the symptoms of different diseases are quite similar with each other. Therefore, the Online Children Skin Diseases Diagnosis System is developed to help parents to recognize the particular children skin diseases which infected their children in short time period. In the development of this system, the concept of expert system is used. This system will provide question list

Manuscript received September 30, 2012; revised January 13, 2013.

The authors are with with University Tun Hussein Onn Malaysia, Batu Pahat, Johor Malaysia (e-mail: munirah@uthm.edu.my, ruhaya@uthm.edu.my, sengfei89@hotmail.com). for parents to choose the symptom as answer and these answers will help in generating diagnosis result.

In this paper, we place our focus on common children skin diseases. The main objective of this paper is to develop expert system for diagnosing the children skin diseases in near future. There are six types of common diseases have been identified for this research; viral rash, eczema, impetigo, urticaria, chicken pox and fifth disease. As mention before, the mistake in diagnosing this skin disease can lead to more serious infection. Hence, this research is important for user with the purpose to assist them in detecting the children skin diseases based on the given symptoms.

Section II provides the related works in expert system, while Section III discusses on design and development of the system while the last section draws our conclusions.

\section{RELATED WORKS}

Artificial Intelligence (AI) is the area of computer science focusing on creating machines that can engage on behaviors that humans consider intelligent. Expert Systems (ES) is one of the artificial intelligence fields, and were developed by the AI community in the mid-1960s. According to Darlington [3], an expert system is a program that attempts to mimic human expertise by applying inference methods to a specific body of knowledge. Rule based expert system is the simplest form of $\mathrm{AI}$ and it is being used in many fields, for example in medical, agriculture or industrial domain. Hence, by using rule based, the knowledge acquire from the expert, for instances doctors, in the form of rules for problem solving [4].

Expert systems have been a highly active research field in the past few years as a mean of conducting medical diagnosis and recommending treatment [5]. There are many expert systems that were developed to diagnose diseases, prescribing drugs or provide suggestive treatment [6]-[10]; but a few for skin diseases diagnosis. Rubin has designed an expert system 'Dermdx', to aid in the interpretation and diagnosis of biopsies of inflammatory diseases of the skin [11]. The system consists of an expert shell, which performs the inference, and a rule-base, which contains the knowledge with which the system operates. Güvenir and Emeksiz have developed an expert system for differential diagnosis of erythemato-squamous diseases incorporating decision by classification algorithm [12]. Samy and Alaa [13], had developed expert system that helps to help dermatologists in diagnosing some of the skin diseases.

\section{DESIGN AND DEVELOPMENT}

In this paper, Online Children Skin Diseases Diagnosis 
System is an expert system that developed for diagnosing the children skin diseases which infected children through online medium. The objective of this system is to enable user recognize skin diseases faced by children and provide user advises or treatments information about children skin diseases in shorter time period. This system is a rule-based system and it using forward chaining technique to retrieve inferences from knowledge base. Further discussion regarding system architecture and context diagram design had been discussed in [14].

TABLE I: SET OF RULES FOR COMMON CHILDREN SKIN DISEASES

\begin{tabular}{|c|c|c|}
\hline Rule & Diseases & Symptoms \\
\hline 1 & Viral Rash & $\begin{array}{l}\text { IF fever } \\
\text { THEN rash is normal red with blanches } \\
\text { pressure }\end{array}$ \\
\hline 2 & & $\begin{array}{l}\text { IF rash is normal red normal red with } \\
\text { blanches pressure } \\
\text { THEN Viral Rash }\end{array}$ \\
\hline 3 & Eczema & $\begin{array}{l}\text { IF extreme itchy } \\
\text { THEN rash is normal redness }\end{array}$ \\
\hline 4 & & $\begin{array}{l}\text { IF rash is normal redness } \\
\text { AND dry skin } \\
\text { THEN Eczema }\end{array}$ \\
\hline 5 & Urticaria & $\begin{array}{l}\text { IF extreme itchy } \\
\text { THEN rash is red circular with center }\end{array}$ \\
\hline 6 & & $\begin{array}{l}\text { IF rash is red circular with center } \\
\text { THEN Urticaria }\end{array}$ \\
\hline 7 & Impetigo & $\begin{array}{l}\text { IF common itchy } \\
\text { THEN rash is honey coloured }\end{array}$ \\
\hline 8 & & $\begin{array}{l}\text { IF rash is honey coloured } \\
\text { AND superficial blister } \\
\text { THEN Impetigo }\end{array}$ \\
\hline 9 & Fifth Disease & $\begin{array}{l}\text { IF fever } \\
\text { THEN rash is lacy red }\end{array}$ \\
\hline 10 & & $\begin{array}{l}\text { IF rash is lacy red } \\
\text { AND slapped check } \\
\text { THEN Fifth Disease }\end{array}$ \\
\hline 11 & $\begin{array}{l}\text { Hand Foot and } \\
\text { Mouth Disease }\end{array}$ & $\begin{array}{l}\text { IF fever } \\
\text { THEN rash is painful with tiny red spot }\end{array}$ \\
\hline 12 & & $\begin{array}{l}\text { IF rash is painful with tiny red spot } \\
\text { AND blister in mouth, hand and foot } \\
\text { THEN Hand Foot and Mouth Disease }\end{array}$ \\
\hline 13 & Chicken Pox & $\begin{array}{l}\text { IF common itchy } \\
\text { AND blister with liquid } \\
\text { AND headache and fever } \\
\text { THEN Chicken Pox }\end{array}$ \\
\hline
\end{tabular}

There are seven types of common diseases that have been identified for this research which are; viral rash, eczema, impetigo, urticaria, chicken pox and fifth disease. The knowledge base of Online Children Skin Diseases Diagnosing System was developed using rules. The set of rules used IF / THEN structure where the information contained in the IF related to other information contained in the THEN part. Knowledge representation helps in creating the rules. Knowledge and facts in the knowledge base will be translated into form of knowledge representation. Table 1 shown thirteen rules based of seven types of common children skin diseases.

This system consist of five types of module; login module, diagnosis module, report module, info module, and management module. However, main modules are diagnosis and management module. In diagnosis module, the symptoms and condition of children skin diseases identified through the answer given for several questions prepared by system. In management module, administrator can manage the system by add, delete, update the latest information of children skin diseases, treatments, symptoms, rules and questions.

Target user for this system is parents and administrator. This system could be an alternative for parents to recognize children skin diseases by answering questions about symptoms and condition of children's skin. While administrator can manage the information about children skin diseases, treatment, symptoms, question, rules data and view the summary report of skin diseases.

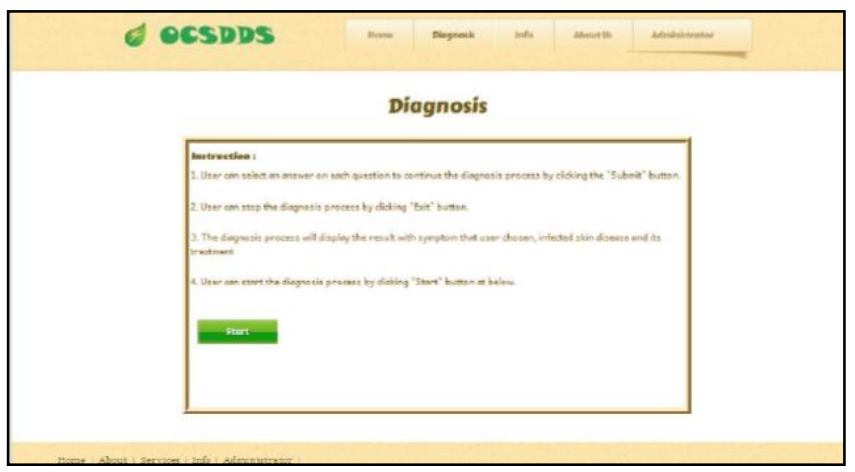

Fig. 1. Diagnosis module's introductory page with instruction

The design of this system is user friendly because it provides a good interaction between systems with user. In this system main page, there are providing skin diseases info and treatment info for user to view by clicking the button. As shown in Fig. 1, the diagnosis page also provides instruction button to help user identify their next step. User can click the "Start" button to start the diagnosis process. Then, a set of question regarding children skin problem symptoms were asked.

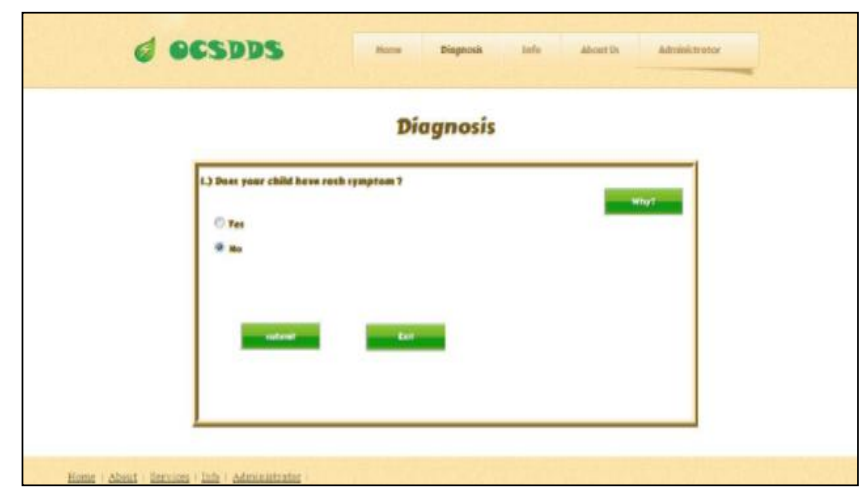

Fig. 2. Displayed question and answer chosen by user.

Fig. 2 shows the questions and answers that chosen by user when answering the questions. As mention before a set of questions regarding children skin problem symptoms were asked. After answering all related questions, this system will generated diagnosis result with explanation of disease info and suggestion treatment. Samples of questions are as the following:

Q1: Does your child have rash symptom?

Q2: Does your child feel itchy?

Q3: How was the itchy feel?

Q4: Does your child have fever?

Q5: Is the rash look like honey, yellow colored? 


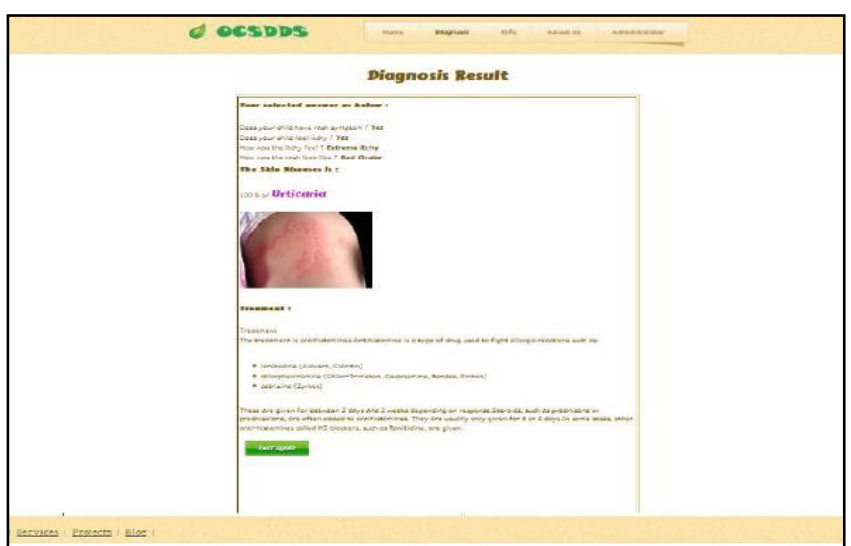

Fig. 3. Diagnosis result interface.

Fig. 3 shows a sample screenshot of possible diagnosis result when user has completed answer all the questions. In this page, user can view the symptoms that chosen from question list, type of children skin disease infected the children, and its treatment. In addition, user can start the diagnosis process again by clicking 'Diagnosis Again' button or quit the diagnosis process by clicking 'Exit' button.

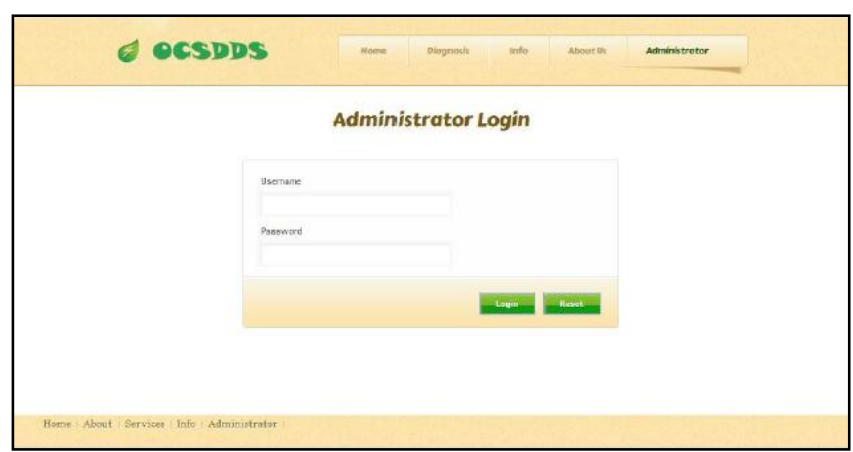

Fig. 4. Login page for administrator.

Besides all these diagnosis pages, Online Children Skin Diseases Diagnosis System provides one special module which is administrator module. This module help and ensure admin manage this system easily and with user friendly interface. Fig. 4 shows a sample screenshot of login page where admin need to login by login interface with username and password before insert, delete and updating any information about skin diseases, symptoms, treatment, rules data and question list in knowledge base. Moreover, they can view the summary report which generated by the system in bar graph and pie graph.

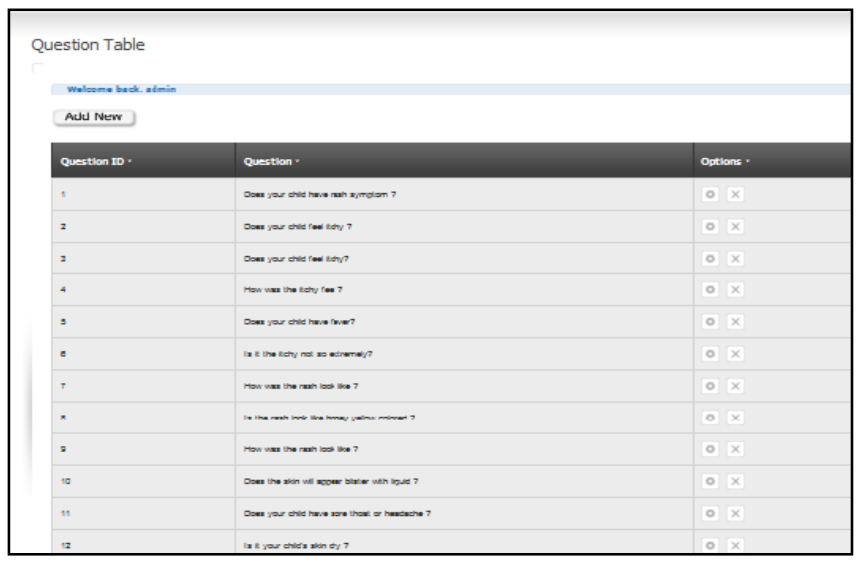

Fig. 5. One of the admin pages for managing diagnosis question.
Fig. 5 shows one of the admin pages for managing question related with children skin diseases diagnosis. In this page, administrator can add new questions that will be added in the knowledge base. Each question has their own questions ID that will be link with the choice of answers. Furthermore, administrator also can delete or update the questions and answer record.

\section{CONCLUSION}

Online Children Skin Disease Diagnosis System was developed using rule based that help user diagnosing and determining children skin diseases and give suggestive treatment in more faster and convenient way through online system. Moreover, this system also help in preventing children skin diseases condition becoming worsen by providing proper treatment information to parents when they used this system.

Although Online Children Skin Disease Diagnosis System has been successfully developed, it still can be enhanced with more diseases, more symptoms and skin diseases pictures or to cater other age range group for instances adult. This improvement too can be applied in the future in hoping to produce a more functional and useful system, yet easy to use and more compatible.

\section{ACKNOWLEDGMENT}

The authors would like to thanks Universiti Tun Hussein Onn Malaysia for the financial support.

\section{REFERENCES}

[1] P. K. Buxton, ABC of Dermatology, Jolly \& Barber Ltd, Great Britain, pp. 1-30, 1991

[2] Eczema Malaysia. (2007). [Online]. Available: http://www.eczema.webs.com/

[3] K. Darlington, The Essence of Expert Systems, Prentice Hall, 2000.

[4] M. Negnevitsky, Artificial Intelligence: A Guide to Intelligent Systems, 2nd ed., Addison-Wesley, 2005

[5] L. G. Kabari and F. S. Bakpo, "Diagnosing Skin Diseases Using an Artificial Neural Network," The 2nd International Conference on Adaptive Science \& Technology, pp. 187-191, 2009

[6] S. S. A. Naser and A. O. A. Zaiter, "An Expert System for Diagnosing Eye Diseases Using CLIPS," Journal of Theoretical and Applied Information Technology, pp. 923-930, 2008.

[7] S. Karim, H. Suryaningsih, and A. Lause, "Expert System for Diagnosing Dengue Fever," presented at Seminar Nasional Aplikasi Teknologi Informasi, 2007.

[8] S. Ismail, A. Novrus, and U. S. Ibrahim, "A Fuzzy Expert System Design for Diagnosis of Prostate Cancer," presented at Internationa Conference on Computer Systems and Technologies, 2003.

[9] J.-C. Chen, T.-S. Liu, C.-S. Weng, and J.-S. Heh, “An Expert System of Coronary Artery Disease in Chinese and Western Medicine," in Proc. of the Conference the Japan Society of Medical Electronics \& Biological Engineering, 2005.

[10] S. K. Patra, D. P. Sahu, and I. Mandal, "An Expert System for Diagnosis of Human Diseases," in Proc. International Journal of Computer Applications, vol. 1, no. 13, 2010.

[11] A. Rubin, "Design of an expert system and its application to dermatopathology," Histopathology, vol. 21, no. 3, pp. 269-274 2007

[12] H. Güvenir and N. Emeksiz, "An expert system for the differential diagnosis of Erythemato-squamous diseases," Expert Systems with Applications, vol. 18, no. 1, pp. 43-49, 2000.

[13] S. S. A. Naser and N. A. Alaa, "A Proposed Expert System for Skin Diseases Diagnosis," Journal of Applied Sciences Research, vol. 4, no. 12, pp. 1682-1693, 2008.

[14] M. Y. Munirah, M. Rozlini, and S. F. Chew, "Design and Rules Development of Online Children Skin Diseases Diagnosis System,' 
presented at International Conference on Information and Knowledge Management, 2012.

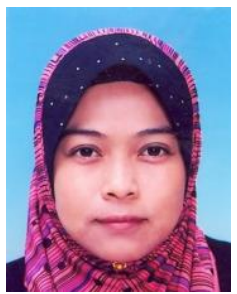

Munirah M. Yusof is a lecturer in Software Engineering Department of University of Tun Hussein Onn Malaysia. Her research interest include intelligent system, case based reasoning and soft computing. Contact her at Software Engineering Department, Faculty of Science Computer \& Information Technology, University Tun Hussein Onn Malaysia; munirah@uthm.edu.my

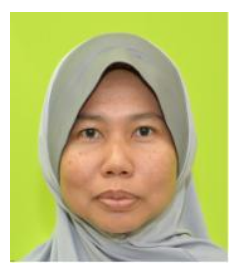

Ruhaya A. Aziz is a lecturer in Software Engineering Department of University of Tun Hussein Onn Malaysia. Her research interests include software requirements engineering, soft computing and industrial computing. Contact her at University of Tun Hussein Onn, Malaysia; ruhaya@uthm.edu.my

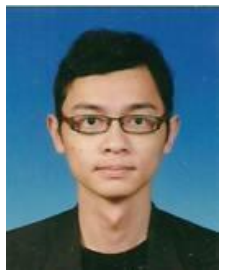

Chew S. Fei is a student in Faculty of Science Computer \& Information Technology, University Tun intelligent system and soft computing. Contact him at Faculty of Science Computer \& Information Technology, University Tun Hussein Onn Malaysia; sengfei89@hotmail.com 